\title{
Modelling daily water temperature from air temperature for the Missouri River
}

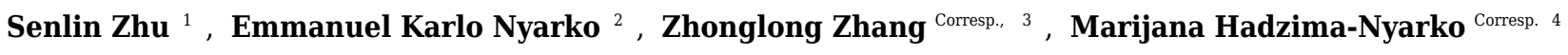 \\ ${ }^{1}$ State Key Laboratory of Hydrology-Water resources and Hydraulic Engineering, Nanjing Hydraulic Research Institute, Nnajing, China \\ 2 Faculty of Electrical Engineering Osijek, University J.J. Strossmayer in Osijek, Osijek, Croatia \\ 3 LimnoTech, Environmental Laboratory, Engineer Research and Development Center, Davis, United States of America \\ 4 Faculty of Civil Engineering Osijek, J. J. Strossmayer University of Osijek, Osijek, Croatia \\ Corresponding Authors: Zhonglong Zhang, Marijana Hadzima-Nyarko \\ Email address: drzhangus@gmail.com,mhadzima@gfos.hr
}

The bio-chemical and physical characteristics of a river are directly affected by water temperature, which thereby affects the overall health of aquatic ecosystems. It is a complex problem to accurately estimate water temperature. Modelling of river water temperature is usually based on a suitable mathematical model and field measurements of various atmospheric factors. In this article, the air - water temperature relationship of the Missouri River is investigated by developing three different machine learning models (Artificial Neural Network (ANN), Gaussian Process Regression (GPR), and Bootstrap Aggregated Decision Trees (BA-DT)). Standard models (linear regression, non-linear regression, and stochastic models) are also developed and compared to machine learning models. Analyzing the three standard models, the stochastic model clearly outperforms the standard linear model and nonlinear model. All the three machine learning models have comparable results and outperform the stochastic model, with GPR having slightly better results for stations No. 2 and 3, while BA-DT has slightly better results for station No. 1. The machine learning models are very effective tools which can be used for the prediction of daily river temperature. The model results can be used to support the Missouri River Recovery Management Plan and Environmental Impact Statement Analysis . 
1 Modelling daily water temperature from air temperature for the Missouri River

2
Senlin Zhu ${ }^{1}$, Emmanuel Karlo Nyarko², Zhonglong Zhang ${ }^{3, *}$, Marijana Hadzima-Nyarko,,

${ }^{1}$ State Key Laboratory of Hydrology-Water resources and Hydraulic Engineering, Nanjing Hydraulic Research Institute, Nanjing, China

${ }^{2}$ Faculty of Electrical Engineering Osijek, University J.J. Strossmayer in Osijek, Osijek, Croatia

${ }^{3}$ LimnoTech, Environmental Laboratory, Engineer Research and Development Center, Davis, United States of America

${ }^{4}$ Faculty of Civil Engineering Osijek, University J.J. Strossmayer in Osijek, Osijek, Croatia

${ }^{*}$ Corresponding author:

Zhonglong Zhang, drzhangus@gmail.com

Marijana Hadzima-Nyarko, mhadzima@gfos.hr 
40

41

42

43

44

45

46

47

48

49

50

51

52

53

54

55

56

57

58

59

60

61

62

63

64

65

66

67

68

69

70

71

72

73

74

75

76

77

78

79

Abstract: The bio-chemical and physical characteristics of a river are directly affected by water temperature, which thereby affects the overall health of aquatic ecosystems. It is a complex problem to accurately estimate water temperature. Modelling of river water temperature is usually based on a suitable mathematical model and field measurements of various atmospheric factors. In this article, the air - water temperature relationship of the Missouri River is investigated by developing three different machine learning models (Artificial Neural Network (ANN), Gaussian Process Regression (GPR), and Bootstrap Aggregated Decision Trees (BADT)). Standard models (linear regression, non-linear regression, and stochastic models) are also developed and compared to machine learning models. Analyzing the three standard models, the stochastic model clearly outperforms the standard linear model and nonlinear model. All the three machine learning models have comparable results and outperform the stochastic model, with GPR having slightly better results for stations No. 2 and 3, while BA-DT has slightly better results for station No. 1. The machine learning models are very effective tools which can be used for the prediction of daily river temperature. The model results can be used to support the Missouri River Recovery Management Plan and Environmental Impact Statement Analysis.

\section{Introduction}

River temperature is an important factor that can be used to determine the health of an aquatic ecosystem. All aquatic species have a specific river water temperature range that they can tolerate and significant changes in river water temperature might detrimentally affect aquatic species (Caissie et al., 2007). For example, studies have shown that high river temperature reduces survival of adult migrating sockeye salmon (Hinch et al., 2012). Migration of fish species in a river is probable especially if the maximum weekly water temperature exceeds its temperature tolerance (Eaton et al., 1995). A fish species may also perish because of osmoregulatory dysfunction if the weekly water temperature drops below a threshold temperature (Mohseni et al., 1998). Warmer temperatures are expected to raise mountain stream temperatures, affecting water quality (dissolved oxygen concentrations) and ecosystem health (Ficklin et al., 2013). Additionally, water temperature affects many bio-chemical processes present in rivers, such as temperature-dependent metabolism (Sandersfeld et al., 2017).

The prediction of river water temperature presents an interesting topic since the water temperature has a significant ecological and economical role (Grbić et al., 2013). Many factors affect river temperature, such as meteorological conditions, river bed conditions, river topography and flow discharge (Caissie, 2006). In addition, anthropogenic activities (Hester and Doyle, 2011) and the hydrological regime (Kelleher et al., 2012; Lisi et al., 2015; Piccolroaz et al., 2016) also impact river temperature prediction. Thus, it is an invaluable task to have a detailed understanding of the ongoing processes related to the river temperature as well as analyze the different impacting factors (Hadzima-Nyarko et al., 2014). Meteorological conditions, especially air temperature, wind speed, solar radiation and humidity, are the factors that have the greatest impact because they determine the heat exchange and fluxes taking place at 
80

81

the surface of the river. In regression analysis of river temperature, air temperature is often used as the only independent variable since it can be used as a substitute for the net exchange in heat fluxes that affect the water surface, and also because air temperature estimates the equilibrium temperature of a water course (Stefan and Preud'homme, 1993; Mohseni and Stefan, 1999; Webb et al., 2003; Caissie, 2006). Additionally, air temperature is widely measured and more available than full energy budget components. Therefore, it is of great importance to study and explain airwater temperature relationship.

Many water temperature models which have been successfully developed and applied in the past years can be generally categorized into deterministic models and statistical models (Caissie, 2006; Benyahya et al., 2007; Cole et al., 2014). Deterministic water temperature models simulate the spatial and temporal variations of river water temperature based on energy balances of heat fluxes and mass balances of flow fluxes in a water body (Hebert et al., 2011). These deterministic models need a great number of input variables, such as river geometry, hydrological and meteorological conditions, and thus are often times impractical and time consuming due to their complexity. Statistical models have been widely used in water temperature predictions because these models are relatively simple and need minimal data inputs. Linear regression models (Morrill et al., 2005; Krider et al., 2013), non-linear regression models (Mohseni et al., 1998; Van Vliet et al., 2012), and stochastic models (Ahmadi-Nedushan et al., 2007; Rabi et al., 2015) have been developed successfully for data relating to different time scales in the past years. Although these statistical models, which link water to air temperatures provide quite simple approaches for water temperature prediction, other statistical models, such as Box Jenkins and non-parametric models (Benyahya et al., 2007), and hybrid statisticalphysical based models as air2water (Toffolon and Piccolroaz, 2015; Piccolroaz et al., 2016) can adequately model the water temperature.

Artificial Neural Network (ANN) models have been applied frequently in prediction and forecasting river water temperatures in recent years (Karaçor et al., 2007; Sahoo et al., 2009; Hadzima-Nyarko et al., 2014; DeWeber and Wagner, 2014; Piotrowski et al., 2015). DeWeber and Wagner (2014) developed an ANN ensemble model to predict the mean daily water temperature using air temperature, landform attributes and forested land cover as predictors. Results showed that under current conditions and future projections of climate and land use changes, the ANN model may prove to be a powerful tool to predict water temperatures, thus it provides valuable information to the management of river ecosystems. Hadzima-Nyarko et al. (2014) generated ANN models and used them to investigate the air and water temperature relationship for the River Drava in Croatia, and concluded that ANN models are suitable for modelling daily mean river temperature.

Though many models have been successfully developed and applied for river water temperature prediction, several key temperature modeling issues have to be noticed, since they may lay the basis for the development of effective river temperature models with medium complexity. (1) The relationship between air temperature and river temperature is non-linear for high or low air temperatures, which has been proved by Mohseni et al. (1998). When air temperatures are close to or below $0{ }^{\circ} \mathrm{C}$, air and water temperatures are no longer synchronized, 
121 leading to a poor relationship between air and river temperatures. The hydrological regime plays

122 a significant role in these cases. (2) River temperature does not respond instantaneously to the

123 variation of air temperature due to thermal inertia, depending on the hydrological regime of the

124 river (Stefan and Preud'homme, 1993; Isaak et al., 2012; Toffolon and Piccolroaz, 2015), thus

125 time lags may need to be considered in air temperature effects for effective water temperature

126 prediction (Benyahya et al., 2008). (3) Estimation problems can be induced by spatial and

127 temporal autocorrelation (Caissie, 2006; Benyahya et al., 2007). (4) Water temperature may be

128 separated into two different components: the long-term periodic component and the fluctuating

129 short-term component. The long-term periodic component can be modeled with simple functions,

130 such as a single invariant sine function, or more complex models, such as Fourier series (Caissie

131 et al., 1998). (5) Many river sites have incomplete data sets even though the amount of observed

132 water temperature data over the world is increasing dramatically (Webb et al., 2008). Very few

133 study areas have a complete matrix of sampling sites and years: data may be missing for an

134 entire year at a site or may be incomplete within a year. Incomplete observed data will affect

135 river water temperature prediction depending on the extent and timing of the missing dataset

136 (Letcher et al., 2016).

137 Selection of appropriate model inputs and the suitable time lags have not been intensively

138 investigated in the literature, especially in the case of estimation of river water temperature and 139 other water quality parameters (Maier and Dandy, 2000). The selection process is usually based 140 on a priori knowledge about water science and the dependence of water temperature on different 141 meteorological factors. Hadzima-Nyarko et al. (2014) tested six different multilayer perception 142 ANN models using the day of year and time lags of the daily mean air temperature as inputs. 143 Suitable model structures were obtained by performing cross-validation. A suitable radial basis 144 function model was also obtained in a similar manner.

145 Piotrowski et al. (2015) compared various ANN models for river water temperature 146 predictions (multi-layer perceptron, product-units, adaptive-network-based fuzzy inference 147 systems and wavelet neural networks) and nearest neighbor method for short term river water 148 temperature predictions. The results showed that simple and popular multilayer perceptron neural 149 networks are not outperformed by more complex and advanced models in most cases. Grbić et al. 150 (2013) applied a Gaussian Process Regression (GPR) model for daily mean water temperature 151 prediction for the river Drava in Croatia. The proposed approach was compared to traditional 152 modelling approaches, including linear regression models, logistic models and stochastic 153 regression models. Decision trees represent a supervised learning method approach popular in 154 machine learning which can be used for predictive modeling. However, to the best knowledge of 155 the authors, it has never been applied in water temperature modelling. This short overview, in 156 which scientists have attempted to predict river water temperature, found a lack of comparison of 157 methods based on ANN, GPR, decision trees and traditional modelling approaches. In some 158 cases, ANN models provided better results, while in other cases, some other regression models 159 did. With this in mind, various machine learning models were developed to explain the 160 relationship between the daily air and river water temperature for the Missouri River by 161 addressing most of the issues listed above. 
162

163

164

165

166

167

168

169

170

171

172

173

174

175

176

177

178

179

180

181

182

183

184

185

186

187

188

189

190

191

192

193

194

195

196

197

198

199

200

201

\section{Materials \& Methods}

\subsection{Study area}

The Missouri River flows more than 3680 kilometers from Three Forks at Montana to St. Louis at Missouri. It is one of the largest tributaries of the Mississippi River. It is an economic lifeline for the watershed, and supports industry, agriculture and outdoor recreations for a long time range. It also provides habitat for wildlife and drinking water for the residents in the whole watershed. However, due to excess uses, the Missouri River encountered some ecological issues. The Missouri River Recovery Program, aiming to replace lost habitat for threatened and endangered wildlife, such as the least tern, pallid sturgeon, and piping plover has been undertaken by the U.S. Army Corps of Engineers (USACE). Water temperature modelling is a key factor in this program because all aquatic organisms need an appropriate temperature to survive. Previously, deterministic water temperature models (HEC-RAS models) have been developed for the Missouri River Recovery Management Plan and Environmental Impact Statement Analysis (Zhang and Johnson, 2016). Due to limited observed data, water temperatures for all inflow boundaries were generated using multiple linear regression approach, which was used to predict river water temperature from air temperatures (Zhang and Johnson, 2016). In this study, machine learning methods were used to further investigate air-water temperature relationships in the Missouri River. Three river stations from the upstream to downstream Missouri River were selected. The geographic locations of the river stations and the corresponding meteorological stations are presented in Fig. 1. The detailed information about these three stations is summarized in Table 1. Fig. 2 shows the time series of the daily mean air temperatures, corresponding water temperatures and available flow discharges for the three stations. Air temperatures are derived from the U.S. Environmental Protection Agency (USEPA) website. Flow discharges are derived from the U.S. Geological Survey (USGS) website. Water temperatures are provided by USACE Omaha and Kansas City Districts.

Figure 1 Geographic locations of the three river stations and meteorological stations

Table 1 Detailed information about the three stations used in this study

Figure 2 Time series of daily averaged air temperatures, corresponding water temperatures and available flow discharge for the three stations (no available flow data for station No. 2)

2.2 Standard water-air temperature regression models

Three standard models, which describe the relationship between air and water temperatures, are compared to the proposed machine learning modelling approaches. These models are the linear regression model, a non-linear regression model and a stochastic regression model.

2.2.1 Linear regression model

For linear regression models, where one dependent variable exists, water temperature is modelled with linear functions. Linear regression models provide a first order estimation of the sensitivity of water temperature on air temperature (Webb and Nobilis, 1997; Kothandaraman, 
202

203

204

205

206

207

208

209

210

211

212

213

214

215

216

217

218

219

220

221

222

223

224

225

226

227

228

229

230

231

232

233

234

235

236

237

238

1971). This simple model is shown in Equation (1):

$$
T_{\mathrm{w}}(\mathrm{t})=A+B T_{a}(t)+\varepsilon(t)
$$

(1) where

$T_{w}(t)$ is water temperature for a given day, $T_{a}(t)$ is air temperature for the same day as water temperature, $A$ and $B$ are regression parameters, and $\varepsilon(t)$ is an error term.

2.2.2 Non-linear regression model

Whether water and air temperature relationship is linear is a key point for linear regression models, and this assumption has been questioned. For example, Mohseni et al. (1998) found a non-linear relationship between water and air temperature, and they developed a non-linear regression model for water temperature prediction based on a logistic S-shaped function. The non-linear regression model proposed by Mohseni et al. (1998) is shown in Equation (2):

$$
T_{\mathrm{w}}(t)=\mu+\frac{\alpha-\mu}{1+e^{\gamma\left(\beta-T_{a}(t)\right)}}
$$

where $\alpha$ is a coefficient which estimates the highest water temperature, $\mu$ is a coefficient which estimates the minimum water temperature, $\beta$ represents the air temperature at the inflexion point, $\gamma$ represents the steepest slope of the logistic S-shaped function.

\subsubsection{Stochastic model}

Stochastic models are normally based on a stochastic time-series analysis function which can predict water temperatures using air temperatures (Caissie et al., 1998). In stochastic models, water temperature is generally modeled as a function of time consisting of two entirely different components, a short-term residual component and a long-term component which is periodic in time. There are several forms of stochastic models. One form is used by Hadzima-Nyarko et al. (2014):

$$
T_{\mathrm{w}}(\mathrm{t})=a+b \sin \left[\frac{2 \pi}{365}\left(t+t_{0}\right)\right]+\beta_{1} T_{a}(t)+\beta_{2} T_{a}(t-1)+\beta_{3} T_{a}(t-2)
$$

where $a, b, t_{0}, \beta_{1}, \beta_{2}, \beta_{3}$ are regression coefficients.

2.3 Water-air temperature relationship models using machine learning procedures

Three different machine learning procedures were implemented for modeling the water-air temperature relationship and compared, namely: ANN, GPR and Bootstrap Aggregated Decision Trees (BA-DT). The models were required to determine the functional dependence of the water temperature $T_{\mathrm{w}}(t)$ on the input variables $t, T_{\mathrm{a}}(t), T_{\mathrm{a}}(t-1)$ and $T_{\mathrm{a}}(t-2)$. The aforementioned input variables or predictors were selected based on the results obtained in Hadzima-Nyarko et al. (2014).

\subsubsection{Artificial Neural Networks}

Artificial Neural Networks are often used to model complex nonlinear functions from observations, which is their biggest advantage. The most popular ANN is the multi-layer backpropagation network, with a basic structure generally consisting of three distinctive layers: the input layer, one or more hidden layers, and the output layer. In such a network, data travels forward through the layers. Data is introduced to the model through the input layer, then it is processed in the hidden layers, and finally output through the output layer. Every layer is made 
239

240

241

242

243

244

245

246

247

248

249

250

251

252

253

254

255

256

257

258

259

260

261

262

263

264

265

266

267

268

269

270

271

272

273

274

275

276

277

up of nodes or neurons which are linked to other neurons in the proceeding layer. With the exception of the neurons in the input layer, all the neurons in the other layers are made up of several components: an activation function, an offset or bias and weights. Common activation functions are logsig and tansig functions, which are sigmoid non-linear functions, and purelin is a linear function.

The training of the network is performed by comparing the desired or measured outputs with the network or model outputs. The difference between these values is then used to adjust the neuron weights. This process is repeated for a sufficiently large amount of training cycles until the desired network output accuracy is achieved.

The stability of ANN model strongly depends on the number of neurons in the hidden layers. A review on approaches to determine the suitable number of hidden neurons within a neural network was performed by Gnana Sheela et al. (2013), where they pointed out that the random selection of the number of hidden neurons may cause errors for the constructed models by either overfitting or underfitting. In this paper, the optimal number of neurons for the ANN model of each station was determined by performing 10 -fold cross validation using the training (or calibration) dataset of each station. For a given station, the optimal number of neurons was determined by gradually increasing the number of neurons from 1 to 10 in the single hidden layer of the ANN model and calculating the mean cross validation error for each given ANN structure. The results of this procedure are displayed in Fig. 3. For the studied three stations, the optimal number of hidden neurons are respectively 3,5 and 6 .

Figure 3 Optimal number of hidden neurons for: a) station 1, b) station 2, c) station 3

\subsubsection{Gaussian Process Regression}

Gaussian Process Regression models are not new in hydrology (Grbić et al., 2013). GPR is a full Bayesian learning algorithm which has been used in diverse applications such as experiment design, multivariate regression, model approximation (Rasmussen and Williams, 2006; Girard et al., 2003; Quiñonero-Candela and Rasmussen, 2005). A process is referred to as a Gaussian processes if it is assumed that the joint probability distribution of model outputs is Gaussian. Compared to other machine learning methods, the advantage of GPR is that it combines various machine learning tasks, which include model training, uncertainty estimation and hyperparameter estimation. In GPR, it is assumed that the output variable measurements of $y$ can be represented as:

$$
y=f(\mathbf{x}(k))+\varepsilon
$$

where $\mathbf{x}$ represents measurements of input variables, $\varepsilon$ represents noise with a Gaussian distribution and variance $\sigma_{\mathrm{n}}^{2}$ and $f$ represents the unknown nonlinear function to be modelled.

The space of functions has a prior probability which is defined as a Gaussian process having mean $m(\mathbf{x})$ and covariance function $\operatorname{cov}\left(\mathbf{x}, \mathbf{x}^{\prime}\right)$ (Rasmussen and Williams, 2006). For a given sample of input variables $\mathbf{x}_{*}$, the output variable is predicted using the predictive probability distribution $p\left(\mathrm{y}_{*} \mid \mathbf{X}, \mathbf{y}, \mathbf{x}_{*}\right)$ with mean and variance: 


$$
\hat{y}_{*}=m\left(\mathbf{x}_{*}\right)+\mathbf{k}_{*}^{\mathrm{T}}\left(\mathbf{K}+\sigma_{n}^{2} \mathbf{I}\right)^{-1}\left(\mathbf{y}-m\left(\mathbf{x}_{*}\right)\right)
$$

$$
\sigma_{y_{*}}^{2}=k_{*}+\sigma_{n}^{2}-\mathbf{k}_{*}^{\mathrm{T}}\left(\mathbf{K}+\sigma_{n}^{2} \mathbf{I}\right)^{-1} \mathbf{k}_{*}
$$

290

291

292

293

294

295

296

297

298

299

300

301

302

303

304

305

306

307

308

309

310

311

312

313

where $\mathbf{I}$ represents the identity matrix, $\mathbf{k}_{*}$ represents a vector which can be defined by $\left[\mathbf{k}_{*}\right]_{i}=$ $\operatorname{cov}\left(\mathbf{x}_{i}, \mathbf{x}_{*}\right), k_{*}=\operatorname{cov}\left(\mathbf{x}_{*}, \mathbf{x}_{*}\right)$ and $\mathbf{K}$ represents a covariance matrix with elements $[\mathbf{K}]_{i, j}=\operatorname{cov}\left(\mathbf{x}_{i}\right.$, $\mathbf{x}_{j}$ ). Thus, it can be seen that compared to classical regression methods where only the parameters are used to determine the model prediction or output, and the model output depends on the training dataset $\mathbf{X}, \mathbf{y}$.

For precise predictions, the available data is used to determine the parameters of the mean and covariance function. The predictive probability distribution is completely defined using these parameters which are often referred to as hyperparameters. The values of the hyperparameters can be obtained by maximizing the log-likelihood function of the training datasets (Rasmussen and Williams, 2006):

$$
\log p(\mathbf{y} \mid \mathbf{X})=-\frac{1}{2} \mathbf{y}^{\mathrm{T}}\left(\mathbf{K}+\sigma_{n}^{2} \mathbf{I}\right)^{-1} \mathbf{y}-\frac{1}{2} \log \left(\left|\mathbf{K}+\sigma_{n}^{2} \mathbf{I}\right|\right)-\frac{n}{2} \log (2 \pi)
$$

(6)

where $n$ is the number of training datasets.

\subsubsection{Bootstrap aggregated decision trees}

In this paper, an ensemble of decision trees is also employed to model the daily river water temperature. A decision tree is a predictive modeling approach popular in machine learning. Specifically, for regression, it is referred to as regression tree. For regression trees, the tree structure is built by binary recursive portioning whereby the data is split into partitions or branches. All data in the training set are initially grouped into the same partition. Then the learning procedure assigns the datasets into the first two branches or partitions, by using every possible binary split of the inputs. The sum of the squared deviations from the mean in the two separate partitions is calculated and the split that minimizes this value is selected. This splitting procedure is then applied to each of the new partitions. The learning process continues until each node reaches a user-defined minimum node size and becomes a terminal node. An ensemble, which combines the predictions from multiple decision trees makes more accurate estimations than a single tree. Since decision trees are sensitive to the specific training data, their output has a high variance. In order to decrease the variance and increase accuracy, bootstrap aggregation or bagging is used (Breiman, 1996). Bagging creates several training datasets by using bootstrap sampling, i.e., by random sampling the original training set with replacement. The regression tree algorithm is applied to each dataset, and then the average amongst the models is used to calculate the estimations for the new data.

2.4 Model evaluation

In this study, the following performance indicators were used to evaluate the model performance: the coefficient of correlation $(R)$, and the root mean square errors (RMSE).

$$
R=\frac{\sum_{i}\left(O V_{i}-O V_{\text {mean }}\right)\left(M V_{i}-M V_{\text {mean }}\right)}{\sqrt{\sum_{i}\left(O V_{i}-O V_{\text {mean }}\right)^{2} \sum_{i}\left(M V_{i}-M V_{\text {mean }}\right)^{2}}}
$$




$$
R M S E=\sqrt{\frac{\sum_{i=1}^{n}\left(M V_{i}-O V_{i}\right)^{2}}{n}}
$$

315

where $O V_{i}$ is the observed water temperature, $O V_{\text {mean }}$ is the averaged observed water temperature for the simulation time period, $M V_{i}$ is the simulated value, $M V_{\text {mean }}$ is the averaged simulated value for the simulation time period, and $n$ is the number of daily estimated and corresponding observed water temperatures at a river monitoring station.

The Nash-Sutcliffe model efficiency coefficient (NSC), defined in the Equation (9), was also used to evaluate the goodness of fit for each model. NSC has a maximum value of 1.0 and has no minimum value. A value of 1.0 indicates a perfect model efficiency.

$$
N S C=1-\frac{\sum_{i=1}^{n}\left(M V_{i}-O V_{i}\right)^{2}}{\sum_{i=1}^{n}\left(O V_{\text {mean }}-O V_{i}\right)^{2}}
$$

In addition to the above performance indicators, the normalized benchmark efficiency (BE) defined, in analogy to the NSC coefficient, in Equation 10 was used to measure the performance improvement of a model over a given benchmark model (Schaefli and Gupta, 2007).

$$
B E=1-\frac{\sum_{i=1}^{n}\left(M V_{i}-O V_{i}\right)^{2}}{\sum_{i=1}^{n}\left(O B_{i}-O V_{i}\right)^{2}}
$$

where $O B_{i}$ is the observed water temperature of the benchmark model.

\section{Results and Discussion}

The test dataset or validation dataset, in this paper was formed by selecting only the data from the year 2013. The remaining data from the original data set was used as the training or calibration dataset. The parameters of the developed models were determined using the training dataset. The test dataset, on the other hand, was used to determine the quality of each of the proposed models. The RMSE was used as the indicator to determine the optimal parameter values, while $R$ and NSC were used to compare the model performances.

\subsection{Standard models}

The parameters of the simple linear regression models, the nonlinear regression models and stochastic regression models were determined using the training dataset and the formulas are presented in Table 2.

Table 2 Regression expressions of standard models for the three stations in this study

The performance indicators of these models obtained for the testing datasets are shown in Table 3. The linear regression models, which describe the relationship between daily water and air temperature of the Missouri River have relatively strong correlation coefficients with $R=0.91$ and $R=0.92$ for station No. 2 and 3. However, for station No. 1, this relationship is relatively weak since $R=0.62$. Generally, the linear regression model performed poorly for water temperature prediction, with $R M S E$ values ranging from 3.41 to 3.94. The Nash-Sutcliffe coefficients $(N S C=0.37,0.82,0.84)$ indicate that the performance of the linear regression model 
348

349

350

351

352

353

354

355

356

357

358

359

360

361

362

363

364

365

366

367

368

369

370

371

372

373

374

375

376

377

378

379

380

381

382

383

384

385

386

387

might not be satisfactory. The results showed that the daily water and air temperature may not be linearly correlated. The non-linear regression model performed a little bit better than linear regression model at station No. 2 and 3. However, for station No. 1, it performed poorly with NSC value being 0.29. A comparison of the performance coefficients of the stochastic model with those of the linear and non-linear models (Table 3) indicates that the stochastic model is a better one due to the higher values of NSC and $R$ on one hand, and lower RMSE values on the other hand.

Table 3 Performance coefficients of the developed models by the testing datasets

\subsection{Machine learning models}

Models of the water-air temperature relationships were generated using ANN, GPR and BADT and compared to the standard models obtained in the previous subsection. The performance coefficients of all the proposed models are shown in Table 3.

Analyzing the data in Table 3 for the models obtained using machine learning methods, it can be noticed that these models outperform the standard models. They all have lower RMSE values and higher $R$ and NSC values than the standard models. All three models obtained using machine learning methods have comparable results, with GPR having slightly better results for station No. 2 and 3, while BA-DT has slightly better results for station No. 1. All three models show high correlation coefficient values with the least value being $R=0.9508$ for BA-DT. For station No. 1, the best model is BA-DT with $R M S E=1.8777$, the correlation coefficient $R=0.9508$ and $N S C=0.7769$. For station No. 2, the best model is GPR with $R M S E=1.5524$, and the correlation coefficient $R=0.9840$ and $N S C=0.9658$. For station No. 3, the best model is GPR with $R M S E=1.4950$, and the correlation coefficient $R=0.9897$ and $N S C=0.9764$. These conclusions are further corroborated by the normalized benchmark efficiency coefficients determined only for the machine learning models using the corresponding linear model as a benchmark model. A higher value indicates better performance improvement over the linear benchmark model compared to the other machine learning models.

The performance of the BA-DT model for station No. 1 is shown in Fig. 4, while the performance of GPR models for stations No. 2 and 3 are respectively presented in Fig. 5 and Fig. 6. It is shown that the BA-DT model performed poor in high water temperature period for station No.1 (Apple Creek). Apple Creek is a small tributary of the Missouri River, and it presents significantly different annual cycle of water temperature and flow discharge compared with stations No. 2 and 3 (Fig. 2). The poor model performance in station No. 1 is likely affected by flow discharge, which has not been included in the models used in this study. Flow discharge can significantly affect water temperature in many rivers, which has been reported by a lot of researchers (Isaak et al., 2010; Van Vliet et al., 2013; Arismendi et al., 2014; Toffolon and Piccolroaz, 2015; Sohrabi et al., 2017).

Figure 4 Performance of BA-DT model for Station No. 1: a) training dataset and b) testing dataset Figure 5 Performance of GPR model for Station No. 2: a) training dataset and b) testing dataset 
Figure 6 Performance of GPR model for Station No. 3: a) training dataset and b) testing dataset

In general, standard regression models are easy to implement. However, their modelling performances are not good enough (Table 3). ANN models are easy to use, able to generalize better and can easily be adapted to include many inputs and outputs. However, it is a tough task to determine the optimal network structure. A decision tree is a predictive modeling approach popular in machine learning. Its implementation for water temperature modelling in this study reveals that this method can be applied for river water temperature modelling. GPR method performs well for water temperature modelling in the Missouri River. For the Missouri River Recovery Management Plan and Environmental Impact Statement Analysis, GPR approach and deterministic models can be integrated to better model water temperature in the river basin. Additionally, further study is needed to analyze the impact of flow discharge on water temperature prediction in the Missouri River.

\section{Conclusions}

Although many factors influence the prediction of river water temperature, the objective of this study was to estimate the daily water temperature of the Missouri River with the aid of only the mean air temperature. In this paper, three standard models and three models obtained using machine learning procedures were used to predict the water temperature of the Missouri river at three locations. Analyzing the three standard models, the stochastic model clearly outperforms the standard linear model and a nonlinear model based on the logistic S-shaped function. On the other hand, all three machine learning models have comparable results and outperform the stochastic model. GPR performs slightly better at station No. 2 and 3, while BA-DT has slightly better results for station No. 1. All three models show high correlation coefficient values with the least value being $R=0.9508$ for BA-DT. Machine learning models are powerful tools for the estimation of daily river temperature. The model results can be used to support the Missouri River Recovery Management Plan and Environmental Impact Statement Analysis.

\section{Acknowledgements}

We would like to thank all those who participated in this study. Many thanks to the Reviewers (Sebastiano Piccolroaz, Gnana Sheela and one anonymous reviewer) for taking the time to provide helpful and constructive feedback on how to improve the manuscript. We would also like to thank the Editorial Team for their time and comments, plus their guidance through this process.

\section{References}

Ahmadi-Nedushan, B., St-Hilaire, A., Ouarda, T.B.M.J., Bilodeau, L., Robichaud, É., Thiémonge, N., Bobée, B., 2007. Predicting river water temperatures using stochastic models: case study of the Moisie river (Quebec, Canada). Hydrological processes 21, 21-34.

Arismendi, I., Safeeq, M., Dunham, J.B., Johnson, S.L., 2014. Can air temperature be used to project influences of climate change on stream temperature? Environmental Research Letters 9, 084015.

Benyahya, L., Caissie, D., St-Hilaire, A., Ouarda, T.B.M.J., Bobée, B., 2007. A review of statistical water 
temperature models. Canadian Water Resources Journal 32, 179-192.

Benyahya, L., St-Hilaire, A., Ouarda, T.B.M.J., Bobée, B., Dumas, J., 2008. Comparison of non-parametric and parametric water temperature models on the Nivelle River, France. Hydrological Sciences Journal 53, 640-655.

Breiman, L., 1996. Bagging predictors. Machine Learning 24, 123-140.

Caissie, D., El-Jabi, N., St-Hilaire, A., 1998. Stochastic modelling of water temperature in a small stream using air to water relations. Canadian Journal of Civil Engineering 25, 250-260.

Caissie, D., 2006. The thermal regime of rivers-a review. Freshwater Biology 51, 1389-1406.

Caissie, D., Satish, M.G., El-Jabi, N., 2007. Predicting water temperatures using a deterministic model: application on Miramichi River catchments (New Brunswick, Canada). Journal of Hydrology 336, 303-315.

Cole, J.C., Maloney, K.O., Schmid, M., Jr, M.K., 2014. Developing and testing temperature models for regulated systems: a case study on the Upper Delaware River. Journal of Hydrology 519, 588-598.

DeWeber, J.T., Wagner, T., 2014. A regional neural network ensemble for predicting mean daily river water temperature. Journal of Hydrology 517, 187-200.

Eaton, J.G., Mccormick, J.H., Stefan, H.G., Hondzo, M., 1995. Extreme value analysis of a fish/temperature field database. Ecological Engineering 4, 289-305.

Ficklin, D.L., Stewart, I.T., Maurer, E.P., 2013. Effects of climate change on stream temperature, dissolved oxygen, and sediment concentration in the Sierra Nevada in California. Water Resources Research 49, 2765 2782.

Girard, A., Rasmussen, C.E., Quiñonero-Candela, J., Murray-Smith, R., 2003. Gaussian Process priors with uncertain inputs - application to multiple-step ahead time series forecasting. In: Becker, S. et al. (Eds.). Advances in Neural Information Processing System 15. MIT Press, Cambridge, Mass, pp. 529-536.

Gnana Sheela, K., Deepa, S.N., 2013. Review on methods to fix number of hidden neurons in neural networks. Mathematical Problems in Engineering 6, 389-405.

Grbić, R., Kurtagić, D., Slišković, D., 2013. Stream water temperature prediction based on Gaussian process regression. Expert systems with applications 40, 7407-7414.

Hadzima-Nyarko, M., Rabi, A., Šperac, M., 2014. Implementation of Artificial Neural Networks in Modeling the Water-Air Temperature Relationship of the River Drava. Water Resources Management 28, 1379-1394.

Hebert, C., Caissie, D., Satish, M.G., El-Jabi, N., 2011. Study of stream temperature dynamics and corresponding heat fluxes within Miramichi River catchments (New Brunswick, Canada). Hydrological Processes 25, 2439-2455.

Hester, E.T., Doyle M.W., 2011. Human impacts to river temperature and their effects on biological processes: A quantitative synthesis. Journal of the American Water Resources Association 47, 571-587.

Hinch, S.G., Patterson, D.A., Hague, M.J., Cooke, S.J., Miller, K.M., Robichaud, D., English, K.K., Farrell, A.P., 2012. High river temperature reduces survival of sockeye salmon (Oncorhynchus Nerka) approaching spawning grounds and exacerbates female mortality. Canadian Journal of Fisheries \& Aquatic Sciences 69, 330-342.

Isaak, D.J., Luce, C.H., Rieman, B.E., Nagel, D.E., Peterson, E.E., Horan, D.L., Parkes, S., Chandler, G.L., 2010. Effects of climate change and wildfire on stream temperatures and salmonid thermal habitat in a mountain river network. Ecological Applications 20, 1350-1371.

Isaak, D.J., Wollrab, S., Horan, D., Chandler, G., 2012. Climate change effects on stream and river 
467

468

469

470

471

472

473

474

475

476

477

478

479

480

481

482

483

484

485

486

487

488

489

490

491

492

493

494

495

496

497

498

499

500

501

502

503

504

505

506

507

temperatures across the northwest U.S. from 1980-2009 and implications for salmonid fishes. Climatic Change 113, 499-524.

Karaçor, A.G., Sivri, N., Uçan, O.N., 2007. Maximum stream temperature estimation of Degirmendere River using artificial neural network. Journal of Scientific \& Industrial Research 66, 363-366.

Kelleher, C., Wagener, T., Gooseff, M., McGlynn, B., McGuire, K., Marshall, L., 2012. Investigating controls on the thermal sensitivity of Pennsylvania streams. Hydrological Processes 26, 771-785.

Kothandaraman, V., 1971. Analysis of water temperature variations in large rivers. Journal of the Sanitary Engineering Division 97, 19-31.

Krider, L.A., Magner, J.A., Perry, J., Vondracek, B., Ferrington, L.C., 2013. Air-water temperature relationships in the trout streams of southeastern Minnesota's carbonate-sandstone landscape. Journal of the American Water Resources Association 49, 896-907.

Letcher, B.H., Hocking, D.J., O’Neil, K., Whiteley, A.R., Nislow, K.H., O’Donnell, M.J., 2016. A hierarchical model of daily stream temperature using air-water temperature synchronization, autocorrelation, and time lags. PeerJ 4, e1727.

Lisi, P.J., Schindler, D.E., Cline, T.J., Scheuerell, M.D., Walsh, P.B., 2015. Watershed geomorphology and snowmelt control stream thermal sensitivity to air temperature. Geophysical Research Letters 42, 3380-3388.

Maier, H.R., Dandy, G.C., 2000. Neural networks for the prediction and forecasting of water resources variables: a review of modelling issues and applications. Environmental Modelling \& Software 15, 101-124.

Mohseni, O., Stefan, H.G, Erickson, T.R., 1998. A non-linear regression model for weekly stream temperatures. Water Resources Research 34, 2685-2692.

Mohseni, O., Stefan, H.G., 1999. Stream temperature/air temperature relationship: a physical interpretation. Journal of Hydrology 218, 128-141.

Morrill, J.C., Bales, R.C., Conklin, M.H., 2005. Estimating stream temperature from air temperature: implications for future water quality. Journal of Environmental Engineering 131, 139-146.

Piccolroaz, S., Calamita, E., Majone, B., Gallice, A., Siviglia, A., Toffolon M., 2016. Prediction of river water temperature: a comparison between a new family of hybrid models and statistical approaches. Hydrological Processes 30, 3901-3917.

Piotrowski, A.P., Napiorkowski, M.J., Napiorkowski, J.J., Osuch, M., 2015. Comparing various artificial neural network types for water temperature prediction in rivers. Journal of Hydrology 529, 302-315.

Quiñonero-Candela, J., Rasmussen, C.E., 2005. A unifying view of sparse approximate Gaussian process regression. Journal of Machine Learning Research 6, 1939-1959.

Rabi, A., Hadzima-Nyarko, M., Sperac, M., 2015. Modelling river temperature from air temperature in the River Drava (Croatia). Hydrological Sciences Journal 60, 1490-1507.

Rasmussen, C.E., Williams, C.K.I., 2006. Gaussian processes for machine learning. Adaptive Computation and Machine Learning, vol. xviii. MIT Press, Cambridge, Mass., p. 48.

Sahoo, G.B., Schladow, S.G., Reuter, J.E., 2009. Forecasting stream water temperature using regression analysis, artificial neural network, and chaotic non-linear dynamic models. Journal of Hydrology 378, 325-342. Sandersfeld, T., Mark, F.C., Knust, R., 2017. Temperature-dependent metabolism in Antarctic fish: do habitat temperature conditions affect thermal tolerance ranges? Polar Biology 40, 1-9.

Schaefli, B., Gupta, H.V., 2007. Do Nash values have value? Hydrological Processes 21, 2075-2080.

Sohrabi, M.M., Benjankar, R., Tonina, D., Wenger, S.J., Isaak, D.J., 2017. Estimation of daily stream water 
508 temperatures with a Bayesian regression approach. Hydrological Processes 31, 1719-1733.

509 Stefan, H.G., Preud'homme, E.B., 1993. Stream temperature estimation from air temperature. Journal of the 510 American Water Resources Association 29, 27-45.

511 Toffolon, M., Piccolroaz, S., 2015. A hybrid model for river water temperature as a function of air temperature 512 and discharge. Environmental Research Letters 10, 114011.

513 Van Vliet, M.T.H, Yearsley, J.R., Franssen, W.H.P, Ludwig, F., Haddeland, I., Lettenmaier, D.P., Kabat, P., 514 2012. Coupled daily streamflow and water temperature modeling in large river basins. Hydrology and Earth 515 System Sciences 16, 4303-4321.

516 Van Vliet, M.T., Franssen, W.H., Yearsley, J.R., Ludwig, F., Haddeland, I., Lettenmaier, D.P., Kabat, P., 2013.

517 Global river discharge and water temperature under climate change. Global Environmental Change, 23, 450518464.

519 Webb, B.W., Nobilis, F., 1997. Long-term perspective on the nature of the air-water temperature relationship: 520 a case study. Hydrological processes 11, 137-147.

521 Webb, B.W., Clack, P.D., Walling, D.E., 2003. Water-air temperature relationships in a Devon river system 522 and the role of flow. Hydrological Processes 17, 3069-3084.

523 Webb, B.W., Hannah, D.M., Moore, R.D., Brown, L.E., Nobilis, F., 2008. Recent advances in stream and river 524 temperature research. Hydrological Processes 22, 902-918.

525 Zhang, Z., Johnson, B.E., 2016. DRAFT HEC-RAS Water Temperature Models Developed for the Missouri 526 River Recovery Management Plan and Environmental Impact Statement. US Army Corps of Engineers, 527 Engineer Research and Development Center, Vicksburg, MS. 
Figure 1

Geographic locations of the three river stations and meteorological stations
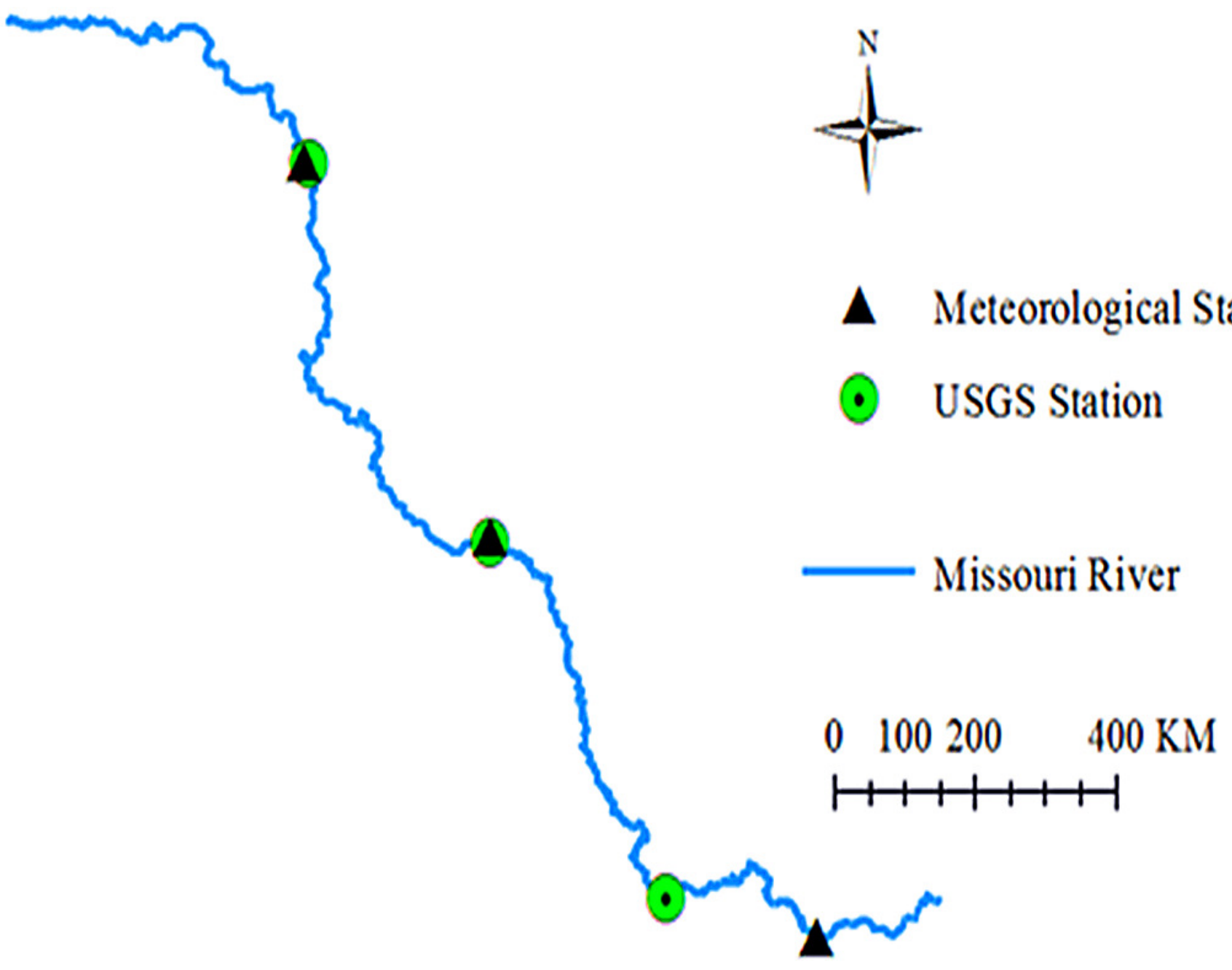
Figure 2 (on next page)

Time series of daily averaged air temperatures, corresponding water temperatures and available flow discharge for the three stations (no available flow data for station No. 2) 


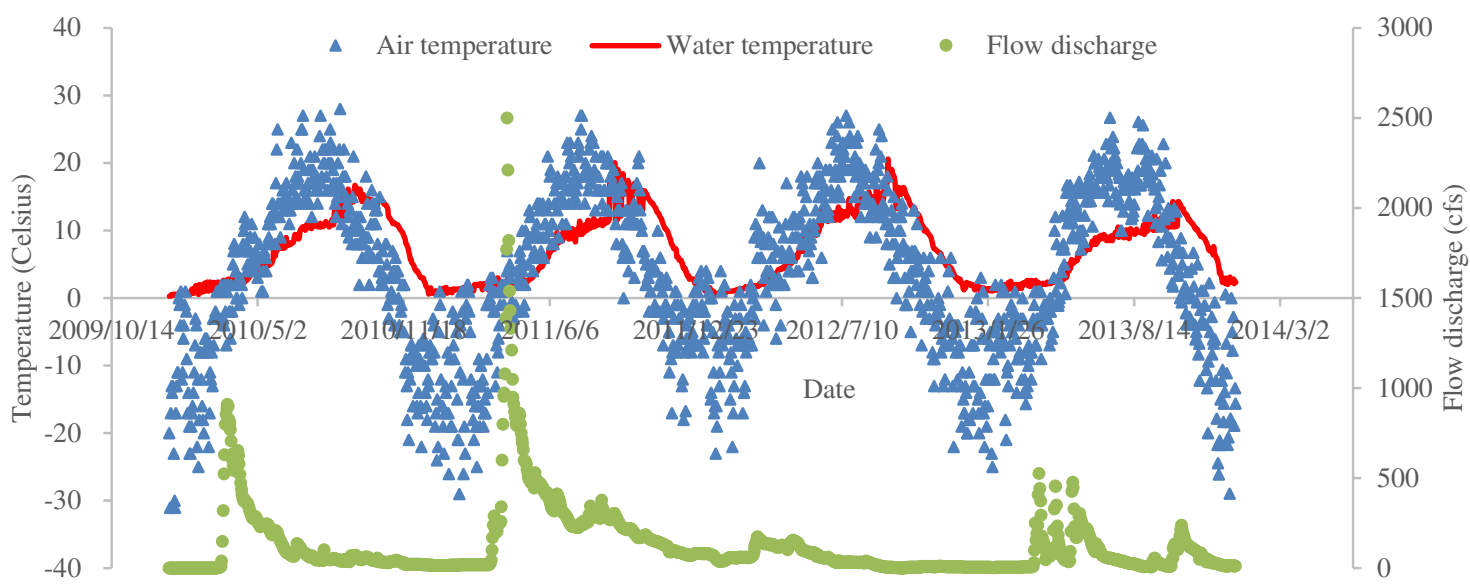

(a) Station No. 1

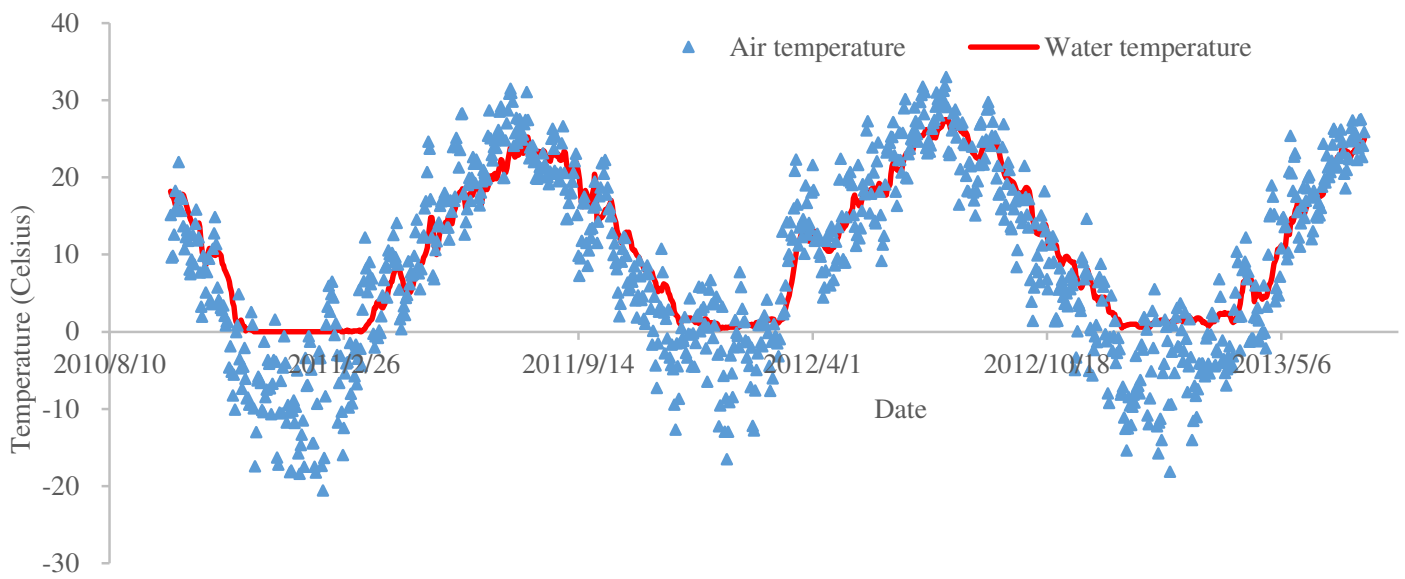

(b) Station No. 2

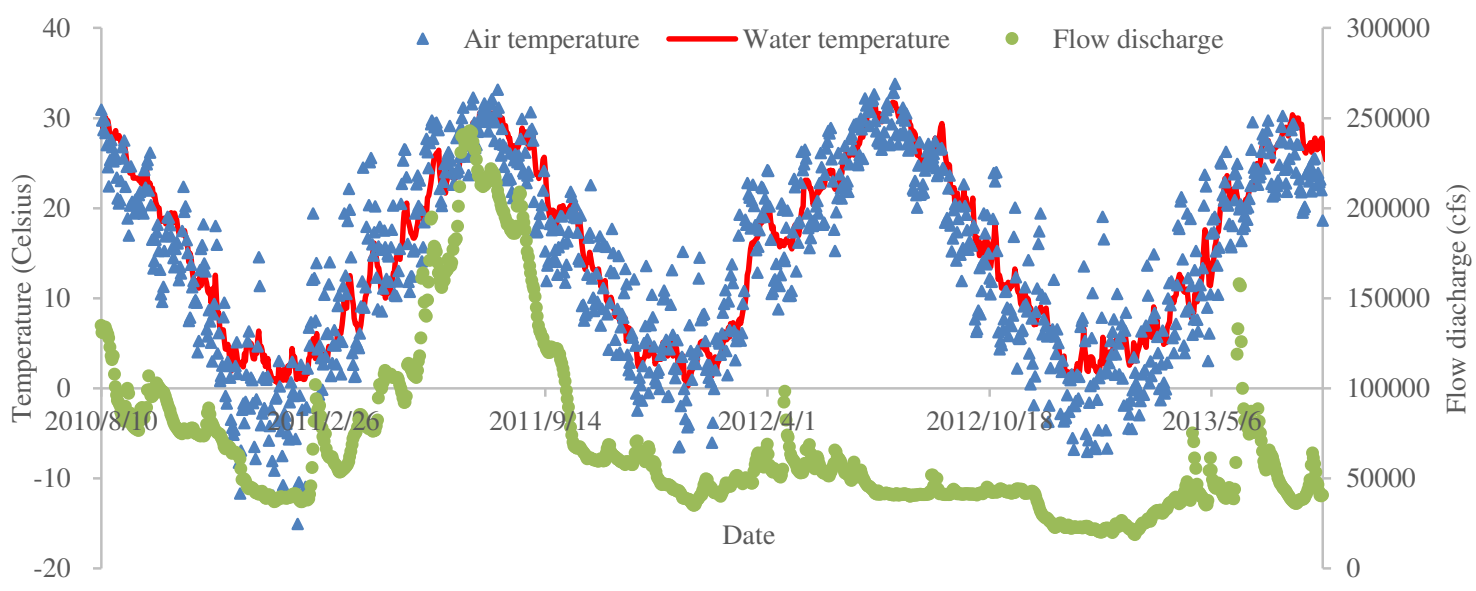

(c) Station No. 3 
Figure 3 (on next page)

Optimal number of hidden neurons for: a) station 1, b) station 2, c) station 3 


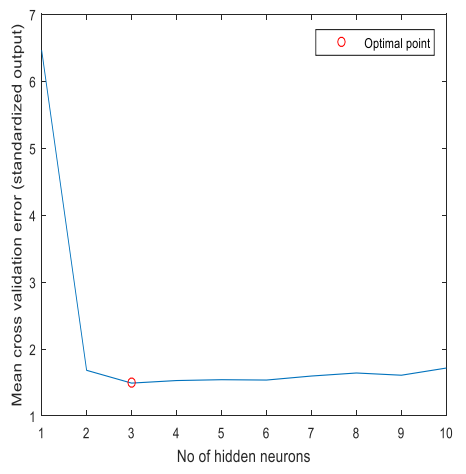

(a)

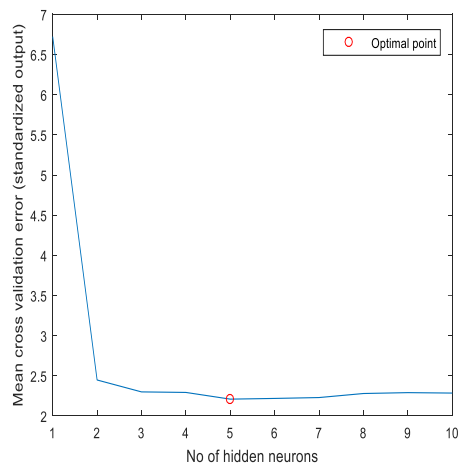

(b)

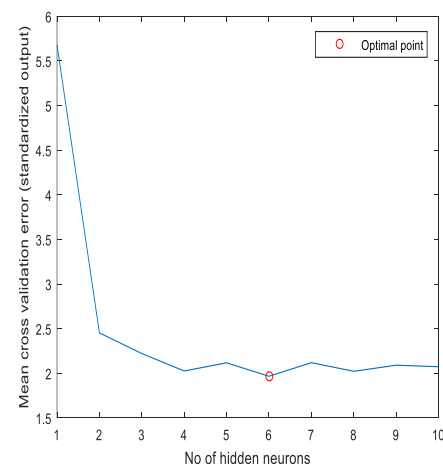

(c) 
Figure 4 (on next page)

Performance of BA-DT model for Station No. 1: a) training dataset and b) testing dataset 


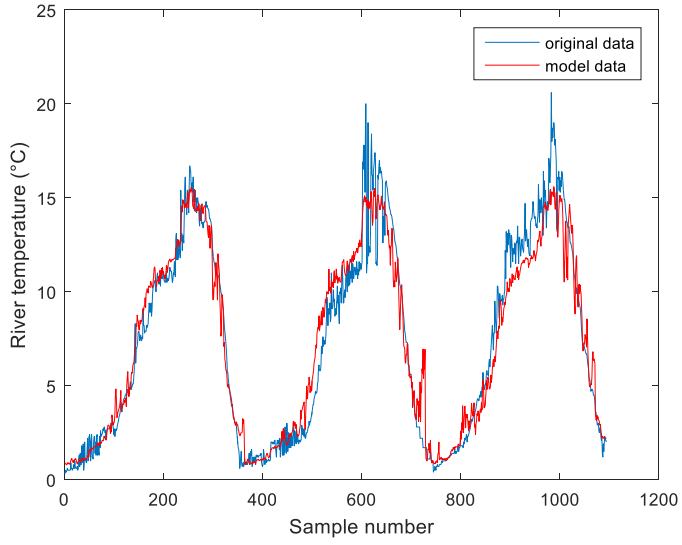

a)

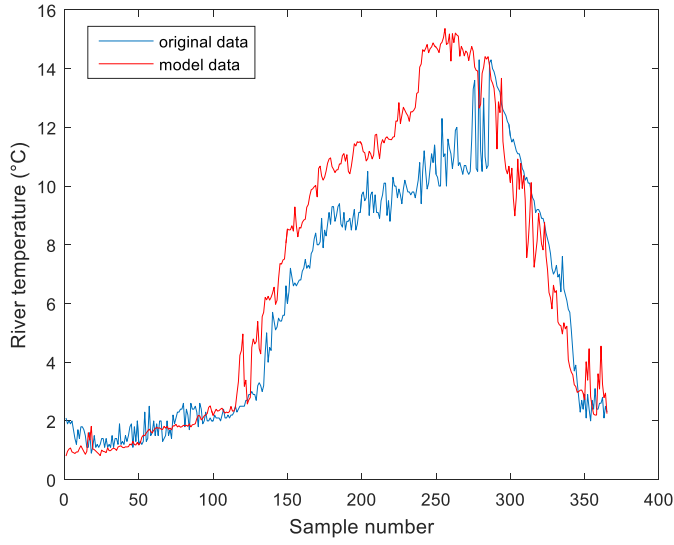

b) 
Figure $\mathbf{5}$ (on next page)

Performance of GPR model for Station No. 2: a) training dataset and b) testing dataset 


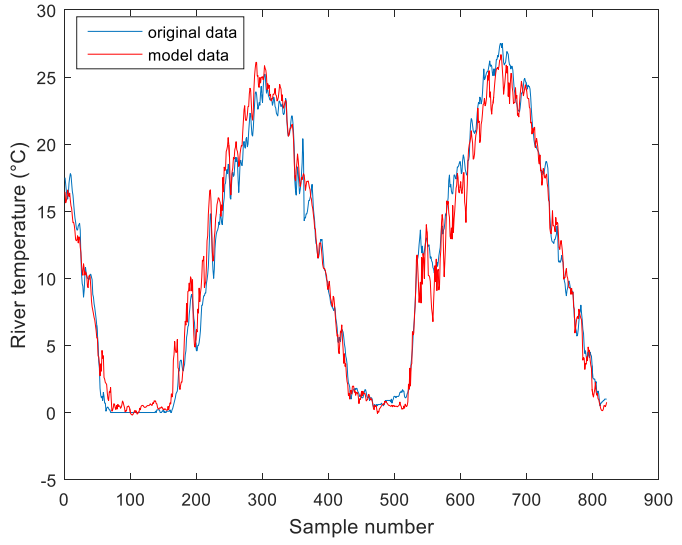

a)

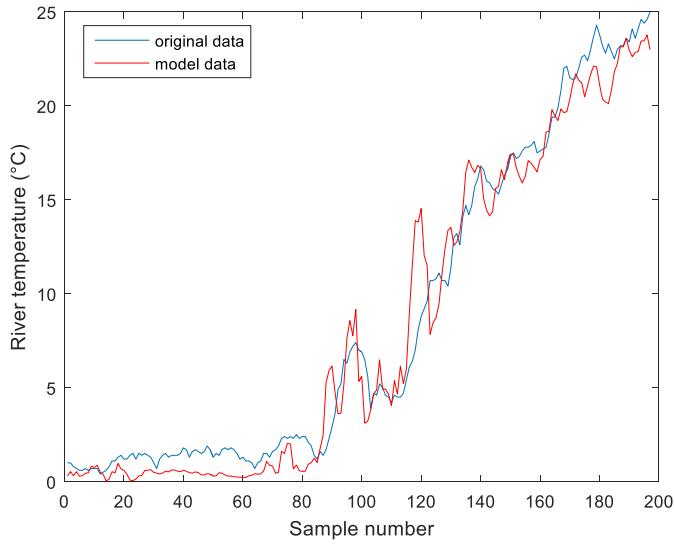

b) 
Figure $\mathbf{6}$ (on next page)

Performance of GPR model for Station No. 3: a) training dataset and b) testing dataset 


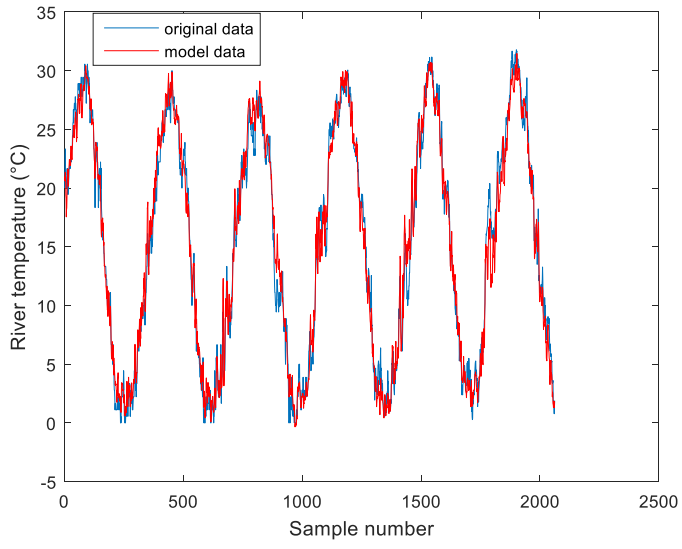

a)

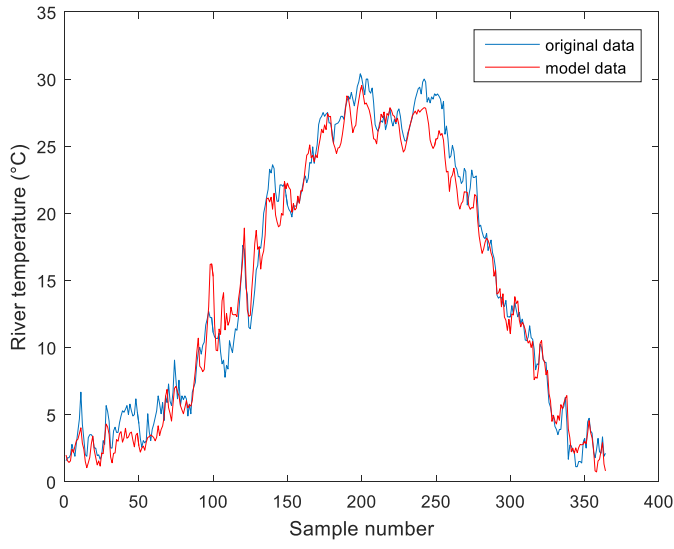

b) 


\section{Table 1 (on next page)}

Detailed information about the three stations used in this study 


\begin{tabular}{|c|c|c|c|c|c|}
\hline Station No. & Station name & Long. & Lat. & Water temperature period & Meteorological station \\
\hline \multirow[t]{2}{*}{1} & Apple Creek Nr Menoken, ND & $-100^{\circ} 39^{\prime} 25^{\prime \prime}$ & $46^{\circ} 47^{\prime} 40^{\prime \prime}$ & $2010 / 1 / 1-2013 / 12 / 31$ & ND320819 \\
\hline & USGS 06349500 & & & & \\
\hline \multirow[t]{2}{*}{2} & Missouri River at Yankton, SD & $-97^{\circ} 23^{\prime} 38^{\prime \prime}$ & $42^{\circ} 51^{\prime} 58^{\prime \prime}$ & $2010 / 10 / 1-2013 / 7 / 16$ & SD726525 \\
\hline & USGS 06467500 & & & & \\
\hline \multirow[t]{2}{*}{3} & Missouri River at Kansas City, MO & $-94^{\circ} 35^{\prime} 17^{\prime \prime}$ & $39^{\circ} 06^{\prime} 43^{\prime \prime}$ & $2007 / 5 / 9-2013 / 12 / 30$ & MO724458 \\
\hline & USGS 06893000 & & & & \\
\hline
\end{tabular}

1 


\section{Table 2 (on next page)}

Regression expressions of standard models for the three stations in this study 


\begin{tabular}{|c|c|c|c|c|}
\hline Station No. & Standard models & \multicolumn{3}{|c|}{ Expressions } \\
\hline \multirow{3}{*}{1} & Linear model & \multicolumn{3}{|c|}{$T_{w}(t)=6.088+0.288 \cdot T_{a}(t)$} \\
\hline & Non-linear model & & $T_{\mathrm{w}}(t)=1.606+\frac{-}{1}$ & $\frac{10.443}{1+e^{0.183\left(3.036-T_{a}(t)\right)}}$ \\
\hline & Stochastic model & $T_{\mathrm{w}}(\mathrm{t})=7.149+6.661 \sin$ & $\left.\frac{2 \pi}{365}(t+578.734)\right]$ & $+0.006 T_{a}(t)+0.011 T_{a}(t-1)+0.014 T_{a}(t-2)$ \\
\hline \multirow{4}{*}{2} & Linear model & \multicolumn{3}{|c|}{$T_{w}(t)=4.971+0.666 \cdot T_{a}(t)$} \\
\hline & Non-linear model & \multicolumn{3}{|c|}{$T_{\mathrm{w}}(t)=\frac{25.639}{1+e^{0.153\left(12.179-T_{a}(t)\right)}}$} \\
\hline & Stochastic model & $T_{\mathrm{w}}(\mathrm{t})=8.998+8.402 \sin$ & $\left.\frac{2 \pi}{365}(t+516.282)\right]$ & $+0.085 T_{a}(t)+0.035 T_{a}(t-1)+0.142 T_{a}(t-2)$ \\
\hline & Linear model & & $T_{w}(t)=3.311$ & $+0.839 \cdot T_{a}(t)$ \\
\hline \multirow[t]{2}{*}{3} & Non-linear model & \multicolumn{3}{|c|}{$T_{\mathrm{w}}(t)=\frac{33.601}{1+e^{0.131\left(16.587-T_{a}(t)\right)}}$} \\
\hline & Stochastic model & $T_{\mathrm{w}}(\mathrm{t})=10.105+8.748 \sin$ & {$\left[\frac{2 \pi}{365}(t+376.967)\right]$} & $+0.193 T_{a}(t)+0.006 T_{a}(t-1)+0.142 T_{a}(t-2)$ \\
\hline
\end{tabular}

1 


\section{Table 3 (on next page)}

Performance coefficients of the developed models by the testing datasets 


\begin{tabular}{cccccc}
\hline Station No. & Models & $R$ & $R M S E$ & NSC & $B E$ \\
\hline \multirow{4}{*}{1} & Linear model & 0.62 & 3.41 & 0.37 & - \\
& Non-linear model & 0.64 & 3.34 & 0.29 & - \\
& Stochastic model & 0.94 & 2.14 & 0.72 & - \\
& ANN & 0.9665 & 1.9471 & 0.7601 & 0.6432 \\
GPR & 0.9664 & 1.9784 & 0.7523 & 0.6317 \\
& BA-DT & 0.9508 & 1.8777 & 0.7769 & 0.6682 \\
& Linear model & 0.91 & 3.53 & 0.82 & - \\
& Non-linear model & 0.94 & 2.99 & 0.87 & - \\
& Stochastic model & 0.98 & 1.86 & 0.95 & - \\
& ANN & 0.9833 & 1.5561 & 0.9657 & 0.7852 \\
& GPR & 0.9840 & 1.5524 & 0.9658 & 0.7862 \\
& BA-DT & 0.9823 & 1.5826 & 0.9645 & 0.7778 \\
& Linear model & 0.92 & 3.94 & 0.84 & - \\
& Non-linear model & 0.93 & 3.62 & 0.86 & -
\end{tabular}

1 